\title{
Prediction and measurement of machining distortion in aluminium alloy 7085
}

\author{
ZHANG Zheng ${ }^{a}{ }^{*}$, LI Liang ${ }^{b}$, YANG Yinfei $^{\mathrm{c}}, \mathrm{HE} \mathrm{Ning}{ }^{\mathrm{d}}$ and ZHAO Wei ${ }^{\mathrm{e}}$ \\ College of Mechanical and Electrical Engineering, Nanjing University of Aeronautics and \\ Astronautics, Nanjing, P. R. China. \\ azhangzheng@nuaa.edu.cn, ${ }^{b}$ liliang@nuaa.edu.cn, 'yyfgoat@nuaa.edu.cn, ddrnhe@nuaa.edu.cn, \\ enuaazw@nuaa.edu.cn
}

Keywords: residual stress; finite element analysis; distortion simulation

\begin{abstract}
It is essential to accurately predict or model the residual stresses in a material resulting from various manufacturing operations. Numerical methods were used in this study to predict the residual stresses after quenching and cold compression of an Al 7085 forged block. Experimental verification was provided by comparing the measured distortions due to a relaxation of the residual stresses with the predictions obtained by using a simulated stress field. The validation was carried out on a simplified structural part. The measured and simulated distortions were found to be in good agreement with each other. The results indicated that part distortion is attributable to the relaxation of bulk residual stresses.
\end{abstract}

\section{Introduction}

During the machining of 7000 series high-strength aluminium alloys, distortion frequently occurs due to residual stresses that are introduced during the quenching step in the heat treatment process. These residual stresses cannot be thermally relieved while maintaining the favourable mechanical properties of the alloy. Therefore, the stresses are overcome by applying a uniform plastic strain by using stretching or cold compression immediately after quenching. However, even after these techniques for stress relief have been carried out, the remaining residual stresses are sufficient to cause distortion in materials, especially those used for aircraft components. Part distortion in the aerospace industry contributes to increased scrap, need for concessions, and the additional manufacturing cost due to distortion correction. It can also contribute to delays in part delivery and failure to meet quality requirements. Furthermore, this can have a knock-on effect on the various stages of aircraft assembly.

Because the contribution of residual stresses is the most important with regards to the ubiquitous presence of distortion, a thorough understanding is crucial for any engineering structure, for designing which liberal safety factors are impractical. The phenomena of residual stress and component distortions have been extensively investigated by scientists from many different disciplines. Prime and Hill [2] investigated the effect of stretching on the stress relief factor of AA7050. Robinson et al. [3] measured the residual stresses formed during quenching and cold compression in AA7449 using both neutron diffraction and the deep hole drilling method. Younger and Eckelmeyer [4] investigated residual stresses and machining distortion in fully quenched plates of AA6061 and AA7075.

Nervi et al. [5] devised a mathematical model for the prediction of distortion in airframe components manufactured from 7050-T7451 aluminium plates. Trummer et al. [6] established a method for accurately determining through-thickness residual stresses in a pre-stretch plate of AA7075. The measured residual stresses were utilized in a finite element model, capable of approximately calculating the shape distortion generated in simple and complex part machining processes employing high speeds.

For most of the problems encountered, the current predictive capabilities are insufficient to provide an adequate knowledge of the residual stress. X-ray diffraction can non-destructively measure only very near-surface stresses. Depth profiling requires the etching away of layers at the spot to be measured. Hole drilling and crack compliance are considered semi-destructive methods. They both 
require removal of local material, with crack compliance being generally more destructive. Layer removal is another destructive method in which whole layers are removed from the entire surface of a component. A complete residual stress profile achieved using layer removal will destroy that part [1]. In a word, none of the destructive methods is suitable as a full-field measurement technique. Diffraction methods, particularly those using synchrotron and neutron diffraction, are difficult to carry out given the limited access, as they can be conducted only at large national or international facilities.

The objective of this paper is to predict residual stresses in a material and the resultant distortion after machining. Experimental verification is provided by comparing the experimentally measured part distortions caused by material removal, with the predictions using a simulated stress field. The validation is accomplished using a simplified structural part machined from a 7085 alloy forging block.

\section{Experimental methods}

\subsection{Material}

A cuboidal forging block $400 \mathrm{~mm} \times 300 \mathrm{~mm} \times 300 \mathrm{~mm}(92 \mathrm{~kg})$ was provided by Southwest Aluminium Corp, Chongqing, China. The composition of the 7085 alloy is presented in Table 1 . The block was solution heat treated at $479 \pm 5 \circ \mathrm{C}$ for $5 \mathrm{~h}$ followed by immersion quenching in agitated water below $60^{\circ} \mathrm{C}$. The specimen was then cold-compressed by $3 \%$ in the transverse direction (T-52 condition, initial size was $400 \times 310 \times 300$, compression reduced by $10 \mathrm{~mm}$ ), and the cold compression was applied over the whole surface in just one application of force (bite). The post-quench delay prior to cold compression was less than $2 \mathrm{~h}$.

Table 1 Composition of the 7085 aluminium alloy (all balanced, wt $\%$ ).

\subsection{FE analysis}

\begin{tabular}{cccccc}
\hline $\mathrm{Zn}$ & $\mathrm{Mg}$ & $\mathrm{Cu}$ & $\mathrm{Fe}$ & $\mathrm{Si}$ & $\mathrm{Zr}$ \\
\hline $7.0-8.0$ & $1.2-1.8$ & $1.3-2.0$ & 0.08 & 0.06 & $0.08-0.15$ \\
\hline
\end{tabular}

In this study, finite element analyses (FEA) were performed for both quenching and the subsequent cold-compression process. For the quenching process, the FEA conditions were identical to the experimental conditions as documented in a report provided by the material supplier.

2.2.1 Conditions for the quenching process

In the quenching process, an aluminium block of 7085 alloy heated uniformly to a temperature of $479^{\circ} \mathrm{C}$ was immersed in water at a temperature of $60^{\circ} \mathrm{C}$ until the block was cooled uniformly. A coupled temperature-displacement analysis was used to (a) determine the temperature variations as a function of time during quenching (heat-transfer analysis) and (b) calculate the residual stresses due to the temperature changes (stress analysis). Table 2 presents the conditions for the quenching process.

Table 2 Quenching process conditions, Elastic Modulus $(E)$ and yield strength for Al 7085 [7]

\begin{tabular}{|c|c|c|}
\hline Parameters & & Value \\
\hline Block temperature before quenching & & $479^{\circ} \mathrm{C}$ \\
\hline Quenchant temperature & & $60^{\circ} \mathrm{C}$ \\
\hline Block temperature after quenching & & $60^{\circ} \mathrm{C}$ \\
\hline Quenching time & & $500 \mathrm{~s}$ \\
\hline $\mathrm{T} /{ }^{\circ} \mathrm{C}$ & $E(\mathrm{MPa})$ & Yield strength (MPa) \\
\hline 50 & 75384 & 500 \\
\hline 100 & 66248 & 455 \\
\hline 150 & 56843 & 410 \\
\hline 200 & 49256 & 315 \\
\hline 250 & 41300 & 182 \\
\hline 300 & 31025 & 93 \\
\hline 400 & 25300 & 21 \\
\hline
\end{tabular}

For values above $400^{\circ} \mathrm{C}$, extrapolation was performed.

A 7085 aluminium block with dimensions of $400 \mathrm{~mm} \times 310 \mathrm{~mm} \times 300 \mathrm{~mm}$ was used for simulation. The 7085 alloyis a relatively new type of tempered aluminium alloy used in the aircraft industry. In our analyses, since material and physical data were not available for Al 7085 tempered aluminium 
forged blocks, data for A1 7075 were used instead. This was a reasonable approximation as both alloys have similar compositions $[8,9]$. Table 3 describes the properties of the material used in this study. FEA of the elastic-perfectly plastic quenching process were performed using MSC Marc version 2012. It was assumed that there were no stresses in the block at the beginning, since the block was heated and kept at $477^{\circ} \mathrm{C}$, a temperature higher than the recrystallization temperature of 7085 aluminium alloy [8]. The FE model used in the present study is illustrated in Fig. 1. This figure also indicates the plane where residual stresses in the $\mathrm{x}, \mathrm{y}$, and $\mathrm{z}$ directions were measured.

Table 3 Thermal expansion, thermal conductivity, and specific heat of Al 7075 alloy at different temperatures [10], as well as the convection coefficient (h) of $\mathrm{Al} 7085$ between aluminium and water [11]

\begin{tabular}{cccccccc}
\hline $\mathrm{T} /{ }^{\circ} \mathrm{C}$ & $\begin{array}{c}\text { Thermal } \\
\text { expansion } \\
\left(10^{-6} / \mathrm{K}\right)\end{array}$ & $\mathrm{T} /{ }^{\circ} \mathrm{C}$ & $\begin{array}{c}\text { Thermal } \\
\text { conductivity, } k \\
(\mathrm{~kW} / \mathrm{m} \mathrm{K})\end{array}$ & $\mathrm{T} /{ }^{\circ} \mathrm{C}$ & $\begin{array}{c}\text { Specific heat, } h_{c} \\
(\mathrm{~J} / \mathrm{kg} \mathrm{K})\end{array}$ & $\mathrm{T} /{ }^{\circ} \mathrm{C}$ & $\begin{array}{c}\text { Convection coefficient, } h \text { (Al and water), } \\
\times 10^{6}\left(\mathrm{~kW} / \mathrm{m}^{2} \mathrm{~K}\right)\end{array}$ \\
\hline 20 & 21.8 & 0 & 0.11 & 20 & 837 & 50 & 200.1 \\
100 & 23.6 & 100 & 0.12 & 100 & 896 & 100 & 4.0 \\
200 & 24.5 & 200 & 0.14 & 200 & 963 & 200 & 13.5 \\
300 & 25.4 & 300 & 0.15 & 400 & 1130 & 300 & 11.0 \\
& 400 & 0.16 & 477 & 1193 & 400 & 7.0 \\
\hline
\end{tabular}

\subsubsection{Compression process conditions}

Compression with a rigid flat die was performed to reduce the residual stresses induced by quenching. A hydraulic press with an average velocity of $20 \mathrm{~mm} / \mathrm{s}$ was used for analysis. After compressing the billet to the predetermined ratios, the die was removed to allow residual stresses to develop. In order to compare compression results, the same locus and plane were used for the quenching results (i.e., the loci were in the middle plane as indicated in Fig. 1). It should be noted that after compression, the block size for FE modelling was $400 \mathrm{~mm} \times 300 \mathrm{~mm} \times 300 \mathrm{~mm}$.

Table 4 lists the FE analysis conditions for the compression process. In the calculation, the dies were assumed to be flat and rigid, a configuration that appears to be reasonable for this initial investigation. The compression ratio was set in compliance with the specimen condition so that the simulated residual stresses could be used to predict subsequent machining distortion.

Table 4 Conditions of compression for FE analysis

\begin{tabular}{ccccc}
\hline Process & $\begin{array}{c}\text { Friction factor billet } \\
\text { and die }(\mu)\end{array}$ & Compression ratio & Compression speed & $\begin{array}{c}\text { Block } \\
\text { temperature }\end{array}$ \\
\hline Compression & 0.4 & $3 \%(10 \mathrm{~mm})$ & $20 \mathrm{~mm} / \mathrm{s}$ & $20^{\circ} \mathrm{C}$ \\
\hline
\end{tabular}

\subsection{X-ray diffraction procedure}

The residual stresses were measured on the surface of the specimen with a PROTO iXRD diffractometer using $\mathrm{Cr}-\mathrm{K} \alpha$ radiation and a position sensitive detector at $20 \mathrm{kV}$ and $4 \mathrm{~mA}$. An isotropic and homogeneous material behaviour was assumed in the measurement. The analysis of the residual stresses was carried out according to the $\sin ^{2}-\Psi$ method using the grid plane 311 with an angle of $2 \theta=140^{\circ}$. At these conditions, the maximum penetration depth of the radiation was $\mathrm{z}=11.5$ $\mu \mathrm{m}$.

The locations for the X-ray diffraction measurements are shown in Fig. 2 (a). An area of 280 $\mathrm{mm} \times 200 \mathrm{~mm}$ on the upside of the specimen was measured using a gauge volume of $70 \mathrm{~mm} \times 50 \mathrm{~mm}$. Due to the fact that residual stress distribution near the edge is relatively complicated, additional test points were added in the measurement, as shown in Fig. 2 (b).

2.4 Validation experiment

Experimental verification was carried out by comparing the part distortions caused by residual stress relaxation in the measurements with the predictions from the simulated stress field. The validation was done on a simplified structural part, as shown in Fig. 3 (a). The simulation of the machining distortion based on the simulated stress field was used to calculate the distortion due to material removal. MSC MARC was employed to perform the linearly elastic simulation. The simulation did not account for machining induced stresses, milling induced temperatures and clamp induced distortions, but only for the balanced residual stresses obtained after material removal. This 
was reasonable as the parts have relatively higher stiffness so that machining induced stresses have a minor effect. In addition, high speed machining techniques can reduce the effect of cutting temperature.

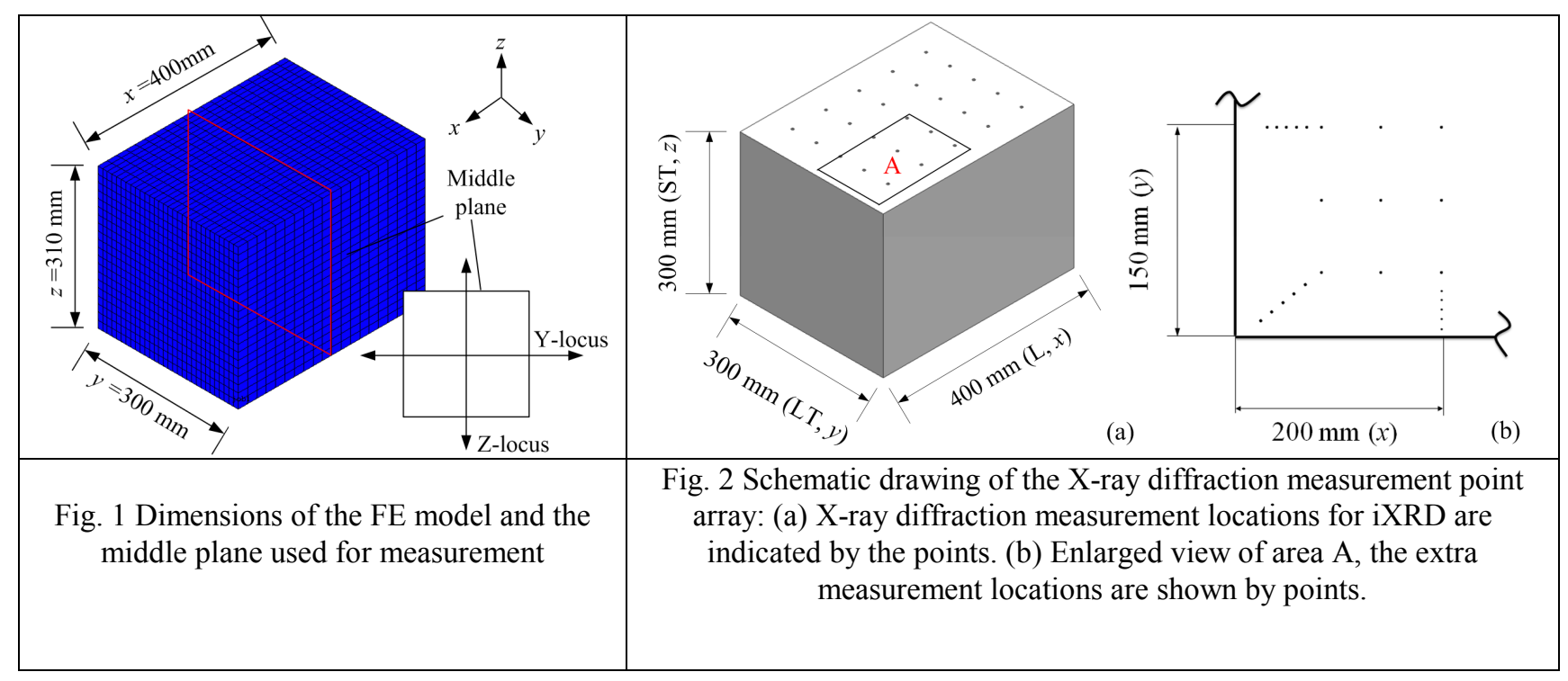

During machining, the axial depth of the cut was $3 \mathrm{~mm}$ and the radial depth was $32 \mathrm{~mm}$. The tool was operated at $15,000 \mathrm{rpm}$ and at a feed rate of $5000 \mathrm{~mm} / \mathrm{min}$. The part was clamped so no machining-related distortion could occur. After the machining process was completed, the part was unclamped and allowed to relax to its distorted state. Part distortions were measured using a laser scanner on both sides of the component, as shown in Fig. 3 (b).
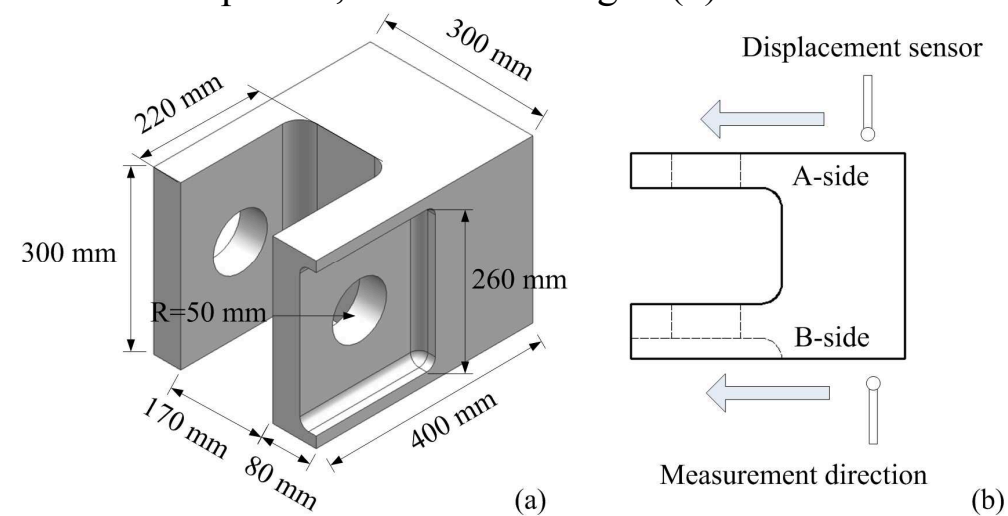

Fig. 3 (a) Schematic illustration of the component. (b) Locations of measurement of machining distortion

\section{Results and discussion}

3.1 Results of the quenching FEA

Fig. 1 illustrates the predicted $\mathrm{x}, \mathrm{y}$ and $\mathrm{z}$ residual stress components at the $\mathrm{y}$ - and $\mathrm{z}$-loci in the middle plane. Figs. 4 present the distribution in the mid-plane of the $\mathrm{x}, \mathrm{y}$, and $\mathrm{z}$ stress components derived from the model. As observed from these figures, the maximum tensile stresses are observed at the centre of the $\mathrm{x}, \mathrm{y}$, and $\mathrm{z}$ residual stresses. The compressive stresses are observed at the surfaces. Since the $\mathrm{x}$-dimension of the block is the largest in value, the $\mathrm{x}$-component of the residual stresses always demonstrates the highest value up to $326 \mathrm{MPa}$ (i.e., the larger the dimension, the higher the temperature gradient, and in turn, the higher the residual stresses). In addition, because the cross section of the block is similar to a square $(310 \mathrm{~mm} \times 300 \mathrm{~mm})$, the $\mathrm{y}$ and $\mathrm{z}$ stress components have a similar distribution along the locus. 

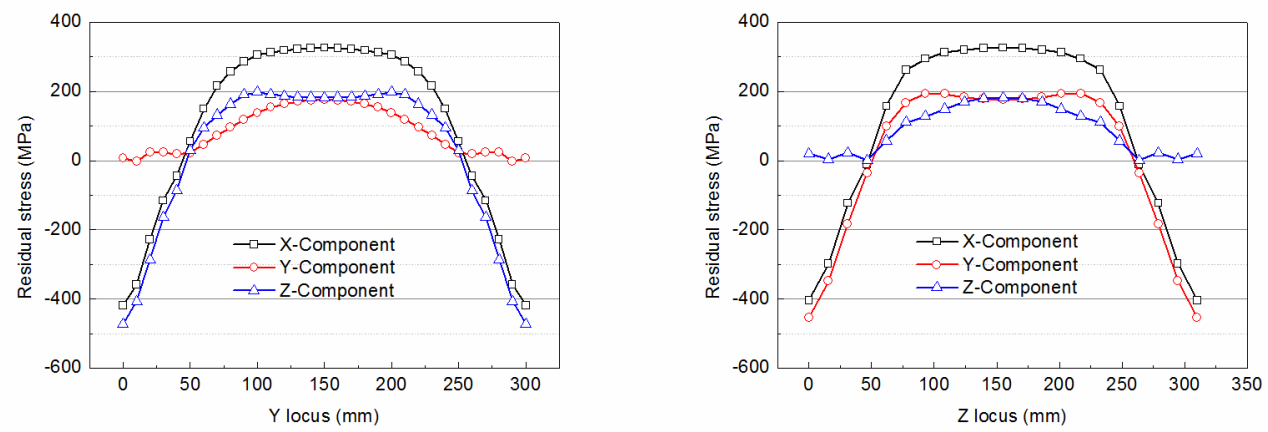

Fig. 4 Predicted residual stresses after quenching along the y- and z-loci in the middle plane

\subsection{Result of the compression FEA}

The residual stresses due to quenching were applied in the model as the initial conditions for the subsequent compression analysis. The compression results are shown in Figs. 5. In this study, all distributions of the stress component compression are non-uniform. After compression of $3 \%$ (compression in the $\mathrm{z}$ direction, ratio $=3 \%$ ), around $65 \%$ stress reduction was achieved by reducing the residual stress values to around $115 \mathrm{MPa}$ (reduction percentages were calculated by using the maximum residual stress values after quenching and compression). The high stress values after compression are usually observed at the edge of the block, a similar propensity as that observed after the quenching process with lower stress magnitudes.
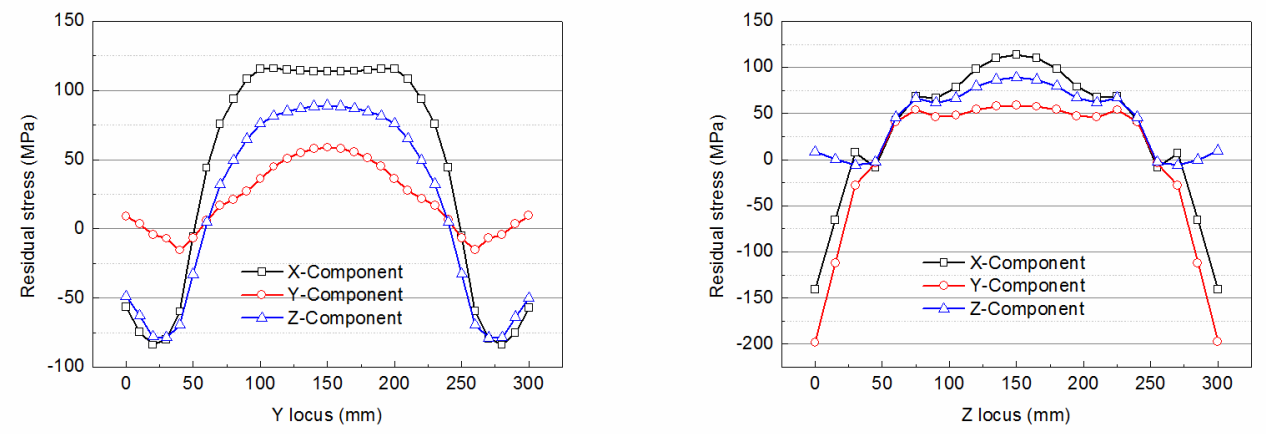

Fig.5 Predicted residual stresses after compression along y- and z-loci in the middle plane

\subsection{Comparison of residual stress}

The simulations and measurements at the surface are detailed in Fig. 6 (Note: only the $\mathrm{x}$-component was measured). It can be seen that the x-component of the stress distribution derived from observation and prediction are similar in shape but different in magnitude. In the central region of the specimen, the stress value is more stable. At the edge of the specimen, the stress distribution varies considerably. The deviation at the edge suggests that partial relaxation of the residual stresses may occur during the compression process. It also may be because of either different cooling rates at the edges or be associated with the issue of meshing.

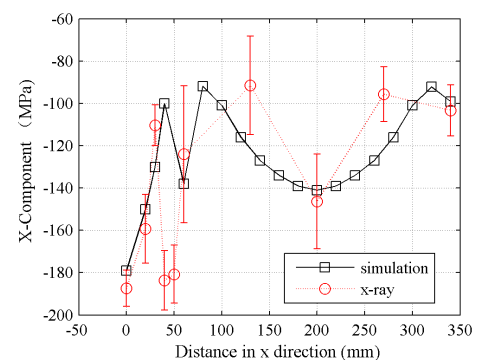

(a)

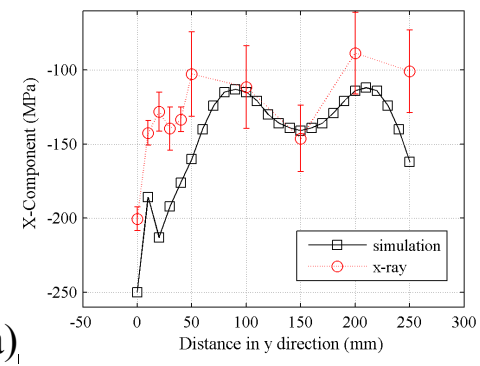

(b)

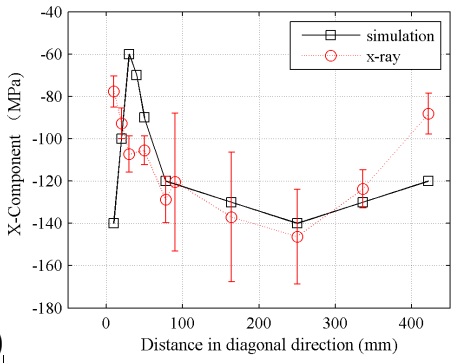

(c)

Fig. 6 Simulation and experimental data of specimen surface residual stress: (a) Measured in the x direction (b) Measured in the $y$ direction (c) Measured in the diagonal direction. 


\subsection{Result of machining distortion}

It can be seen in Fig. 7 that the part is deformed significantly after machining. Results of the machining distortion are presented in Fig. 8. Due to material removal and relaxation and redistribution of the bulk residual stresses, the slot in the component deformed inward by about $1 \mathrm{~mm}$. It was also observed that the prediction based on a simulated stress field helped accurately forecast the inclination of the distortion. The measurements and simulations were similar in form but different in magnitude. The following are considered the primary sources of error and uncertainty and are listed in the order of importance. (1) Errors in the estimated residual stresses in the material. Accurate material parameters need to be used for analysis. The through-thickness residual stress profile should be measured. (2) Variation in the material properties. It was assumed that the material properties are constant for the entire block. (3) Effect of machining induced stress. The effect of machining induced stress on distortion tends to increase with decreasing thickness. To put it briefly, the results indicate that part distortion arising from machining can be attributed to the relaxation of the bulk residual stresses as a result of material removal.

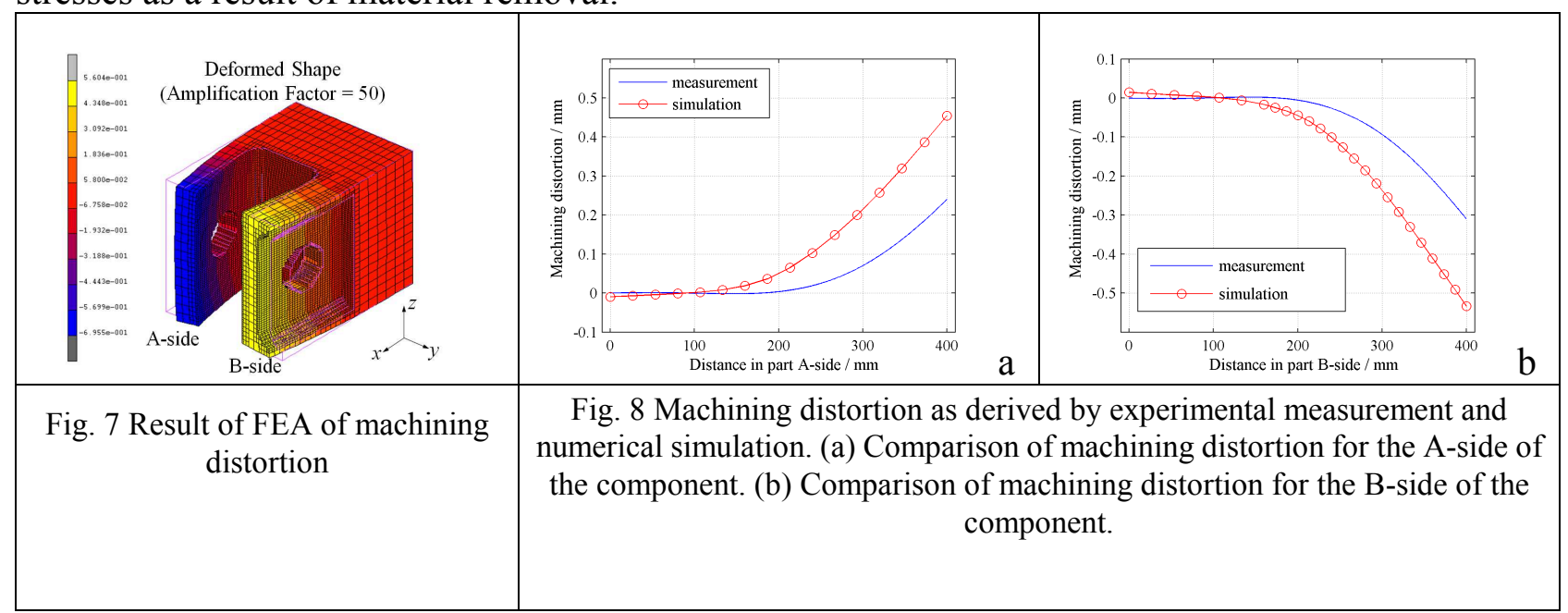

\section{Conclusions}

The influence of bulk residual stress distribution causes significant part distortions after the machining of large structural components. The simulation approach, presented in this paper, was developed to predict the part distortions taking into account the part geometry and bulk residual stress distribution within the workpiece. This presents possibilities to avoid or minimize part distortions in advance by adapting new machining strategies or process conditions.

\section{References}

[1] M.B. Prime, Applied Mechanics Reviews, 52 (1999) 75-96.

[2] M.B. Prime, M.R. Hill, Scripta Materialia, 46 (2002) 77-82.

[3] J.S. Robinsona, S. Hossainb, C.E. Trumanb, A.M. Paradowska, D.J. Hughes, R.C. Wimpory, M.E. Fox, Materials Science and Engineering A, 527 (2010) 2603-2612.

[4] M.S. Younger, K.H. Eckelmeyer, Sandia Report, SAND2007-6811.

[5] S. Nervi, B.A. Szabó, K.A. Young, AIAA JOURNAL, 47 (2009) 1635-1641.

[6] V. R. Trummer, D. Koch, A. Witte, J.F. dos Santos, P.M.S.T. de Castro, The International Journal of Advanced Manufacturing Technology, 68 (2013) 2271-2281.

[7] W. Shaohui, Master dissertation, Central South University, Changsha, China, 2011. (in Chinese)

[8] Alcoa Green Letter Volume I, Alcoa 7085 Die Forgings 7th Generation Structural Solutions, 3rd Edition, August, 2006.

[9] The Aluminium Association, Aluminium Standards and Data, March 1997.

[10] M. Koc, J. Culp, T. Altan, Journal of Materials Processing Technology 174 (2006) 342-354.

[11] J.D. Watto, Computational Modeling and Optimization of Bulk Residual Stress in Monolithic Aluminium Die Forgings. Residual Stress Summit 2010, Lake Tahoe. 